Article

\title{
Fabrication of Zinc Oxide-Xanthan Gum Nanocomposite via Green Route: Attenuation of Quorum Sensing Regulated Virulence Functions and Mitigation of Biofilm in Gram-Negative Bacterial Pathogens
}

\author{
Fohad Mabood Husain ${ }^{1, *}$, Imran Hasan ${ }^{2}{ }^{(0}$, Faizan Abul Qais ${ }^{3}{ }^{\circledR}$, Rais Ahmad Khan ${ }^{4}{ }^{(}$, \\ Pravej Alam 5 (1) and Ali Alsalme ${ }^{4, *(\mathbb{C})}$ \\ 1 Department of Food Science and Nutrition, College of Food and Agriculture Sciences, King Saud University, \\ Riyadh 11451, Saudi Arabia \\ 2 Department of Chemistry, Chandigarh University, Mohali 140413, India; imranhasan98@gmail.com \\ 3 Department of Agricultural Microbiology, Faculty of Agricultural Sciences, Aligarh Muslim University, \\ Aligarh 202002, India; faizanabulqais@gmail.com \\ 4 Department of Chemistry, King Saud University, Riyadh 11451, Saudi Arabia; krais@ksu.edu.sa \\ 5 Department of Biology, College of Science and Humanities in Al-Kharj, Prince Sattam bin \\ Abdulaziz University, Al-Kharj 11942, Saudi Arabia; alamprez@gmail.com \\ * Correspondence: fhusain@ksu.edu.sa (F.M.H.); aalsalme@ksu.edu.sa (A.A.)
}

Received: 14 November 2020; Accepted: 3 December 2020; Published: 5 December 2020

\begin{abstract}
The unabated abuse of antibiotics has created a selection pressure that has resulted in the development of antimicrobial resistance (AMR) among pathogenic bacteria. AMR has become a global health concern in recent times and is responsible for a high number of mortalities occurring across the globe. Owing to the slow development of antibiotics, new chemotherapeutic antimicrobials with a novel mode of action is required urgently. Therefore, in the current investigation, we green synthesized a nanocomposite comprising zinc oxide nanoparticles functionalized with extracellular polysaccharide xanthan gum (ZnO@XG). Synthesized nanomaterial was characterized by structurally and morphologically using UV-visible spectroscopy, XRD, FTIR, BET, SEM and TEM. Subinhibitory concentrations of $\mathrm{ZnO@XG} \mathrm{were} \mathrm{used} \mathrm{to} \mathrm{determine} \mathrm{quorum} \mathrm{sensing} \mathrm{inhibitory} \mathrm{activity} \mathrm{against}$ Gram-negative pathogens, Chromobacterium violaceum, and Serratia marcescens. ZnO@XG reduced quorum sensing (QS) regulated virulence factors such as violacein $(61 \%)$, chitinase $(70 \%)$ in C. violaceum and prodigiosin $(71 \%)$ and protease $(72 \%)$ in S. marcescens at $128 \mu \mathrm{g} / \mathrm{mL}$ concentration. Significant $(p \leq 0.05)$ inhibition of biofilm formation as well as preformed mature biofilms was also recorded along with the impaired production of EPS, swarming motility and cell surface hydrophobicity in both the test pathogens. The findings of this study clearly highlight the potency of ZnO@XG against the QS controlled virulence factors of drug-resistant pathogens that may be developed as effective inhibitors of QS and biofilms to mitigate the threat of multidrug resistance (MDR). ZnO@XG may be used alone or in combination with antimicrobial drugs against MDR bacterial pathogens. Further, it can be utilized in the food industry to counter the menace of contamination and spoilage caused by the formation of biofilms.
\end{abstract}

Keywords: xanthan gum; zinc oxide; nanocomposite; quorum sensing; biofilm; virulence; S. marcescens; C. violaceum 


\section{Introduction}

Xanthan gum is a natural anionic extracellular polysaccharide. The non-toxic and biocompatible nature of this polymer makes it quite useful for the food sector [1]. The inorganic particles, such as metals, can easily be adsorbed onto it to form a stable emulsion without altering the interfacial tension. This is a Food and Drug Administration (FDA)-approved biopolymer for the food industry [2,3]. Zinc is an essential micronutrient and therefore extensively prescribed for its nutritional supplement in case of deficiency for human health. As zinc is biocompatible, there is not much risk associated with public health and is used as food coating materials [4]. The unique property of zinc oxide nanoparticles is exploited as promising antibacterial, antibiofilm, or antivirulence candidates (Al-Shabib et al., 2018; Sirelkhatim et al., 2015, [5,6]).

Tremendous growth and spread of multidrug resistance (MDR) among microbial pathogens have become a global concern for human health countries [7]. The worldwide deaths of human-caused by antimicrobial resistance (AMR) is a major contributor to global mortality after cancer and cardiovascular diseases [8]. The problem caused by AMR has reached an alarming situation, and if not action is taken, it is expected to cause more global mortality than cancer by $2050[9,10]$. The infections caused by MDR pathogens are an epidemiological concern and worsen the treatment of infectious diseases by diminishing the therapeutic effectiveness of antibiotics [11,12]. Moreover, AMR is not only problematic for public health but also poses an extra burden on the environment and livestock. The first half 20th century is regarded as the golden era for the discovery and development of antibiotics. Nearly $70 \%$ of all antibiotics used so far were discovered by 1960. After this, there was poor progress in the antibiotic drug discovery and in the last four decades, only a few antibiotics exhibiting a novel mechanism of action are discovered [13]. The injudicious use of antibiotics in public health and health and environment creates a selection pressure that results in the development of AMR among microbial pathogens [14,15].

The risk of AMR development is so much that even the antibiotics of the last generation cannot be entrusted for prolonged applications. Hence, there are two major issues associated with the discovery or development of antibacterials; the first is to find or make new chemotherapeutic antimicrobials with novel modes of action, and the second is to minimize the risk of development of AMR against the discovered antimicrobials. This has led the researchers to focus on the development of alternative anti-infective strategies to combat AMR.

Quorum sensing (QS) is a communication system occurring via chemical signaling that operates as a function of the density of the bacterial population [16]. These chemical signal molecules are called autoinducers (AIs). Certain phenotypes of bacteria are only expressed when their population has reached a certain threshold value. Many clinically important traits of bacteria, such as virulence production, biofilms formation, expression of drug-resistant genes, are controlled via QS [17]. As the bacterial population increases, the concentration of AIs increases and triggers the expression of QS-regulated genes by transcriptional regulation when it reaches a certain limit [18]. Biofilms are the microbes residing in a biopolymeric matrix. Earlier, it was thought that bacteria live in a planktonic state. However, it was discovered that most of the bacteria form complex structures called biofilms [19]. A large number of bacterial infections are encouraged or caused by the formation of biofilms by the pathogenic or opportunistic pathogens $[20,21]$. One of the novel strategies in antibacterial drug discovery is to selectively target the bacterial quorum sensing and biofilms. Among new drug candidates, natural/biocompatible products and nanoparticles have proven as an important therapeutic antimicrobial alternative (Husain et al., 2019; Qais et al., 2018, 2019, [22-24]).

In this study, green synthesis of zinc oxide xanthan gum (ZnO@XG) nanocomposite was done. The antiquorum-sensing potential of ZnO@XG was tested against biosensor strains of Gram-negative bacteria. The QS controlled violacein production, and chitinase activity was tested in C. violaceum. QS regulated virulence traits of $S$. marcescens such as prodigiosin production, and protease production were also assessed at subinhibitory concentrations of ZnO@XG. Further, the effect on biofilm formation, preformed biofilm and factors such as EPS production, swarming motility, and cell 
surface hydrophobicity that contribute to the development of biofilm against both the bacteria was also studied. This is probably the first study assessing the quorum sensing and biofilm inhibitory potential of green synthesized polysaccharide-zinc oxide nanocomposite.

\section{Materials and Experimental Methods}

\subsection{Chemicals}

Xanthan gum extracted from Xanthomonas Campestris biological grade was purchased from Sigma-Aldrich (Bangalore, India). Zinc nitrate $\left(\mathrm{Zn}\left(\mathrm{NO}_{3}\right)_{2} \cdot 6 \mathrm{H}_{2} \mathrm{O}\right.$ white crystals) and sodium hydroxide $(\mathrm{NaOH})$ were purchased from Merck (Mumbai, India). All the chemical materials were used without any purification or refinement. All the aqueous solutions were prepared using deionized water.

\subsection{One-Pot Green Synthesis of ZnO@XG Nanoparticles}

The Nanoparticles were consolidated by using a chemical coprecipitation scheme using an ecological green route [25]. In a 3 necked round-bottomed flask, a $100 \mathrm{~mL}$ solution of $0.45 \mathrm{M} \mathrm{Zn}$ $\left(\mathrm{NO}_{3}\right)_{2} \cdot 6 \mathrm{H}_{2} \mathrm{O}$ was taken and placed under magnetic stirring $(900 \mathrm{rpm})$ for $30 \mathrm{~min}$ to obtain homogeneity. A solution of $2.3 \%$ xanthan gum was prepared by dissolving $2.3 \mathrm{~g}$ powder in $100 \mathrm{~mL}$ deionized water with vigorous stirring at $40^{\circ} \mathrm{C}$ for $2 \mathrm{~h}$ to obtain a complete bubble-free homogeneous solution. Now the blended solution of xanthan gum with $20 \mathrm{~mL}$ of $0.1 \mathrm{M} \mathrm{NaOH}$ solution was added drop-by-drop to the aqueous ionic solution of $\mathrm{Zn}^{2+}$ in order to extend the reducing character of xanthan gum to the bulk of $\mathrm{Zn}^{2+}$. The mixture remained on vigorous stirring under observation at $40^{\circ} \mathrm{C}$, and the progress of the reaction was checked by taking small aliquots of the reaction mixture at different time intervals to verify using UV-vis spectroscopy (Figure 1). Finally, after $8 \mathrm{~h}$, a white precipitated colloid was obtained from which the product was isolated using a centrifuge (REMI rpm 8500). The product was squeezed using deionized water seven to eight times for the efficient removal of nonreactive species and dried in a hot air oven for $3 \mathrm{~h}$ at $60^{\circ} \mathrm{C}$.

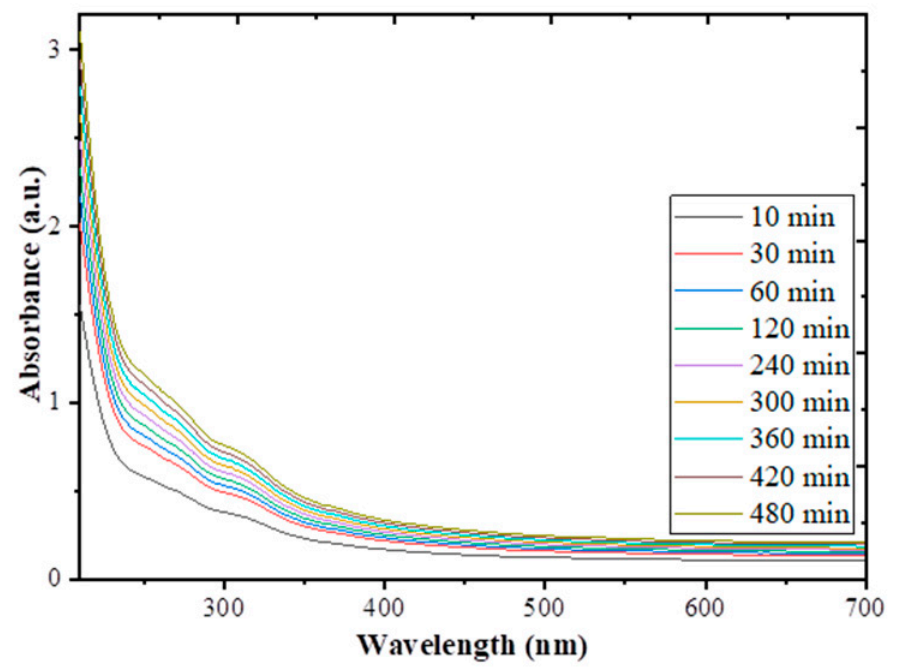

Figure 1. Time-dependent UV-vis spectra for green synthesized ZnO@XG nanocomposite.

\subsection{Analytical Techniques Used for Characterization}

The prepared nanocomposite and its crystal structure were characterized by several characterization techniques such as FTIR, XRD, SEM-EDX, TEM, BET and UV-Vis. The type of bonding and functional groups present in the synthesized material was investigated by using Fourier-transform infrared spectroscopy (FTIR) PerkinElmer (PE1600, PerkinElmer, Waltham, MA, USA) in the frequency range of $400-4000 \mathrm{~cm}^{-1}$ with transmission mode. The crystal phases of the synthesized material were collected on an X-ray diffractometer (A Rigaku Ultima 1 V, Woodlands, TX, USA). The morphologies of 
the sample were analyzed by using scanning electron microscopy (SEM; JEOL GSM 6510LV, JEOL, Tokyo, Japan). The elemental size and dispensation of the sample were examined by JEM 2100 (Tokyo, Japan) transmission electron microscopy (TEM). For the analysis of aliquots of ZnO@XG samples during the synthesis process, Shimadzu UV-1900 UV-vis double beam spectrophotometer was taken into consideration. The specific surface areas of the synthesized material were tested on Micromeritics Tristar II (Micromeritics, Atlanta, GA, USA) and calculated using the Brunauer-Emmett-Teller (BET) method.

\subsection{Bacterial Strains}

Chromobacterium violaceum ATCC 12472 and Serratia marcescens ATCC 13880 were used to evaluate the QS and biofilm inhibitory property of the synthesized nanocomposites. Stock cultures of all the test bacteria were maintained on nutrient-agar under refrigeration and subcultured in Luria-Bertani (LB) broth for $24 \mathrm{~h}$. Overnight culture (1\%) was added to the fresh LB medium [the final optical density (OD) was adjusted to 0.1 at $600 \mathrm{~nm}]$.

\subsection{Determination of Minimum Inhibitory Concentration (MIC)}

The minimum inhibitory concertation of ZnO@XG against test bacteria was assessed by microbroth dilution assay as described previously [26,27]. Briefly, bacteria were cultured in the presence of different concentrations (1024-0.125 $\mu \mathrm{g} / \mathrm{mL})$ of ZnO@XG. Post incubation, TTC $(10 \mu \mathrm{L})$ was added to each well and incubated at room temperature for $20 \mathrm{~min}$ to observe a change in color. The lowest concentration at which the development of pink color was not observed was termed as the MIC.

\subsection{Violacein Inhibition Assay}

Violacein pigment production was quantified spectrophotometrically using the previously described protocol [28]. Briefly, C. violaceum 12,472 (CV12472) was grown overnight in the absence and presence of sub-MICs $(16-128 \mu \mathrm{g} / \mathrm{mL})$ of $\mathrm{ZnO} @ X \mathrm{XG}$ at $30^{\circ} \mathrm{C}$. Post incubation, $1 \mathrm{~mL}$ culture was centrifuged (10,000 rpm) for $5 \mathrm{~min}$, and violacein pigment was extracted from the pellet using $1 \mathrm{~mL}$ DMSO. The extracted mixture was centrifuged to pellet out the bacterial cells. The optical density (OD) of supernatant was recorded at $585 \mathrm{~nm}$ using a UV-2600 spectrophotometer (Shimadzu, Kyoto, Japan).

\subsection{Chitinolytic Activity}

A dye-release assay involving chitin azure was employed to quantify the chitinase produced by CV12472 [29,30]. Briefly, $100 \mathrm{~mL}$ bacterial supernatant obtained from treated and untreated bacteria was mixed with $1 \mathrm{~mL}$ phosphate buffer containing $10 \mathrm{mg}$ chitin azure and incubated overnight at $37^{\circ} \mathrm{C}$. The insoluble substrate was pelleted out, and absorbance was read at $585 \mathrm{~nm}$.

\subsection{Prodigiosin Assay}

Production of red-colored prodigiosin in ZnO@XG treated and untreated S. marcescens was quantified using the method described previously [31]. Briefly, pellets obtained from the overnight grown cultures of $S$. marcescens were resuspended in $1 \mathrm{~mL}$ acidified ethanol and vortexed vigorously. The mixture was centrifuged at 13,000 rpm for $5 \mathrm{~min}$, and the resulting supernatant was read for absorbance at $534 \mathrm{~nm}$.

\subsection{Protease Assay}

The proteolytic activity in cell-free supernatant of $S$. marcescens was assessed using azocasein as the substrate [32]. ZnO@XG treated and untreated cultures of S. marcescens were grown overnight on shaking, and cell-free supernatants (CFS) were collected by centrifugation (7000 $\mathrm{g}$ for $10 \mathrm{~min}$ ). Subsequently, CFS $(75 \mu \mathrm{L})$ was added to $2 \%$ azocasein $(125 \mu \mathrm{L})$ in $0.25 \mathrm{~mol}$ Tris $(\mathrm{pH} 8.0)$ and incubated for a half-hour at $37^{\circ} \mathrm{C}$. The reaction was stopped with the addition of $10 \%$ Trichloroacetic acid, and the 
mixture was centrifuged for $10 \mathrm{~min}$. The absorbance of the resultant supernatant was measured at $440 \mathrm{~nm}$.

\subsection{Biofilm Inhibition Studies}

\subsubsection{Microtiter Plate Assay}

Overnight grown test pathogens $C$. violaceum and S. marcescens were diluted in wells containing fresh Tryptic soy broth, sub-MICs of ZnO@XG was added to wells and incubated at $37^{\circ} \mathrm{C}$ for $24 \mathrm{~h}$ duration. Wells were decanted to get rid of unattached cells and washed with sterile water. Then bound cells were stained with crystal violet and incubated. After $15 \mathrm{~min}$ incubation, the dye was removed from wells, and thorough washing was done to remove excess stain. The absorbance of each well was measured at $585 \mathrm{~nm}$ to quantify the biofilm inhibition (Al-Shabib et al., 2020, [33]).

\subsubsection{Confocal Laser Scanning Microscopic (CLSM) Visualization of Biofilm Structure}

CLSM analysis of biofilm of ZnO@XG treated and untreated test pathogens formed on glass coverslips were performed using the protocol described previously (Al-Shabib et al., 2020, [34]). Biofilm was developed on glass coverslips placed in 24 well tissue culture plates as described above. CLSM imaging was done on coverslips stained with $0.1 \%$ acridine orange in the dark under JEOL-JSM $6510 \mathrm{LV}$ confocal laser scanning microscope.

\subsubsection{Quantification of EPS}

EPS was quantified from test pathogens grown in the presence and absence of sub-MICs of $\mathrm{ZnO} @ X \mathrm{XG}$ at $30{ }^{\circ} \mathrm{C}$ for $24 \mathrm{~h}$. Incubated cultures were centrifuged, ice-cold ethanol (3 volumes) was added to the resultant supernatant, and the mixture was left at $4{ }^{\circ} \mathrm{C}$ for $18 \mathrm{~h}$. Subsequently, the mixture was centrifuged, and the pellet was dissolved in $1 \mathrm{~mL}$ deionized water [35]. EPS was quantified using the standard method for the estimation of sugars, as described previously [36].

\subsubsection{Swarming Motility}

Effect of sub-MICs of ZnO@XG on the swarming motility of C. violaceum and S. marcescens was determined by point inoculating the bacteria on LB soft agar plates and incubating the plates at $30^{\circ} \mathrm{C}$ for $18 \mathrm{~h}$. Briefly, LB soft agar plates (\% agar w/v) were prepared, containing ZnO@XG. No treatment was given to control plates. Bactria were point-inoculated in soft agar plates and incubated under static conditions. Post incubation, the diameter of the swarm was measured in treated and control plates to evaluate the inhibition of swarming motility [37].

\subsubsection{Microbial Adhesion to Hydrocarbon (MATH) Assay}

MATH assay was used to evaluate the effect of ZnO@XG on cell surface hydrophobicity of the test pathogens [38]. Optical density (OD) of treated and untreated bacteria was recorded at $600 \mathrm{~nm}$. Then, toluene was added to each set and vortexed for $10 \mathrm{~min}$, and the mixture was left for separation of phases. The aqueous phase was collected, and the absorbance was recorded at $600 \mathrm{~nm}$. Percent of hydrophobicity was calculated using the following formulae:

$$
\% \text { hydrophobicity }=[1-\text { OD after vortexing } / \text { OD before vortexing }] \times 100 \%
$$

\subsection{Disruption of Preformed Biofilms}

Biofilms were allowed to develop for $24 \mathrm{~h}$ in the wells of microtiter plates. Non-adhering cells were washed away, new sterile TSB with or without sub-MICs of ZnO@XG was supplemented to each well and MTP was incubated at $37^{\circ} \mathrm{C}$ for $24 \mathrm{~h}$. Then, unbound cells were removed by washing and adhering cells were stained with crystal violet. Absorbance was recorded at $585 \mathrm{~nm}$, as described earlier (Al-Shabib et al., 2020, [39]). 


\section{Results and Discussion}

Nanocomposites of zinc oxide and xanthan gum were synthesized according to the scheme depicted in Figure 2. Synthesized nanomaterial was characterized by structurally and morphologically using various spectroscopic and microscopic techniques

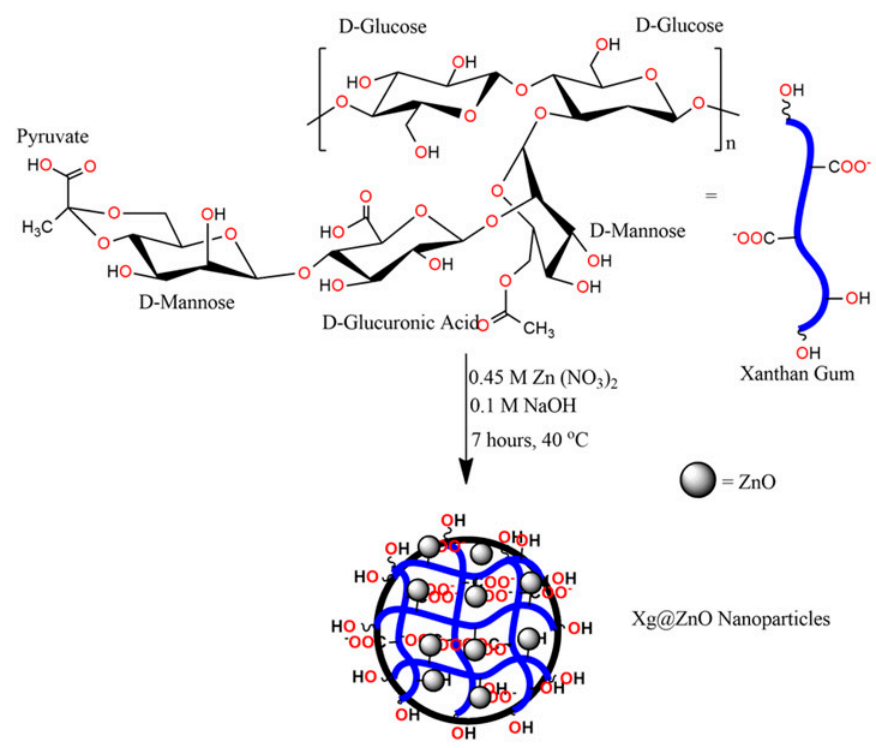

Figure 2. Proposed scheme for the synthesis of $\mathrm{ZnO@XG} \mathrm{nanocomposite.}$

\subsection{FTIR}

The Fourier-transform infrared spectra of xanthan gum and ZnO@XG NPs are displayed in Figure 3. The FTIR spectra of XG (Figure 3a) are demonstrated the peak at 3417 (-OH stretching), 2932 (aliphatic $-\mathrm{CH}$ stretching), 1736 (-C=O stretching), 1614, $1414 \mathrm{~cm}^{-1}$ (COO- symmetric and asymmetric stretching) and the peaks between $1049-1249 \mathrm{~cm}^{-1}$ (pyranoid C-O-C ring stretching) [40]. The FTIR spectra of ZnO@XG NPs in Figure $3 b$ represents all the characteristic peaks from XG and $\mathrm{ZnO}$ with vibrational frequency, e.g., 606, 774 ( $\mathrm{Zn}-\mathrm{O}$ bond stretching), 1049-1221 (C-O-C XG pyranoid ring), 1409, 1596 (COO- symmetric and asymmetric stretching), 1736 (-C=O stretching), 2923, 2850 (C-H aliphatic stretching of XG), $3307 \mathrm{~cm}^{-1}$ (-OH stretching). The shifting in the carboxylic acid vibrational frequency suggests that the reduction as well stabilization of the $\mathrm{Zn}^{2+}$ into $\mathrm{ZnO}$ was done through the donation of electrons (lone pairs) from oxygen from an XG-O-Zn type lattice [41,42].

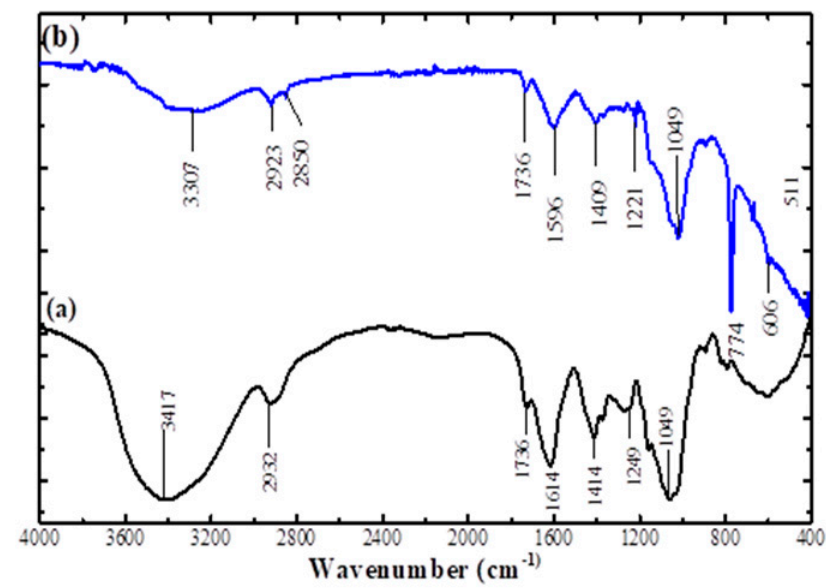

Figure 3. FTIR spectra of (a) xanthan gum (XG) (b) ZnO@XG nanocomposite. 


\section{2. $X R D$}

The XRD spectra of bulk ZnO (black line) and ZnO@XG NPs (blue line) is given in Figure 4. The XRD of bulk ZnO NPs represented the characteristic peaks of ZnO NPs at $2 \theta$ values of $31.68^{\circ}$, $32.82^{\circ}, 36.16^{\circ}, 47.48^{\circ}, 56.49^{\circ}, 58.64^{\circ}, 62.71^{\circ}$, and $67.81^{\circ}$, which correspond to miller indices values of (100), (002), (101), (102), (110), (103), (112), (200) crystalline plane of ZnO (JCPDS 89-0510) [43]. While looking at the spectra of ZnO@XG NPs, the characteristics peaks from ZnO NPs appeared at $2 \theta$ value $30.75^{\circ}(\mathrm{ZnO}), 33.63^{\circ}(\mathrm{ZnO}), 35.96^{\circ}(\mathrm{ZnO})$ and $52.77^{\circ}(\mathrm{ZnO})$ with corresponding miller indices values of (110), (002), (101), (200) and (202). The spectrum reveals the peaks with shifted diffraction angle ( $2 \theta$ values) from the precursor values with reduced intensity of $\mathrm{ZnO}$ due to functionalization with XG biopolymer chains, which imparted a small amorphous character to the nanoparticles.

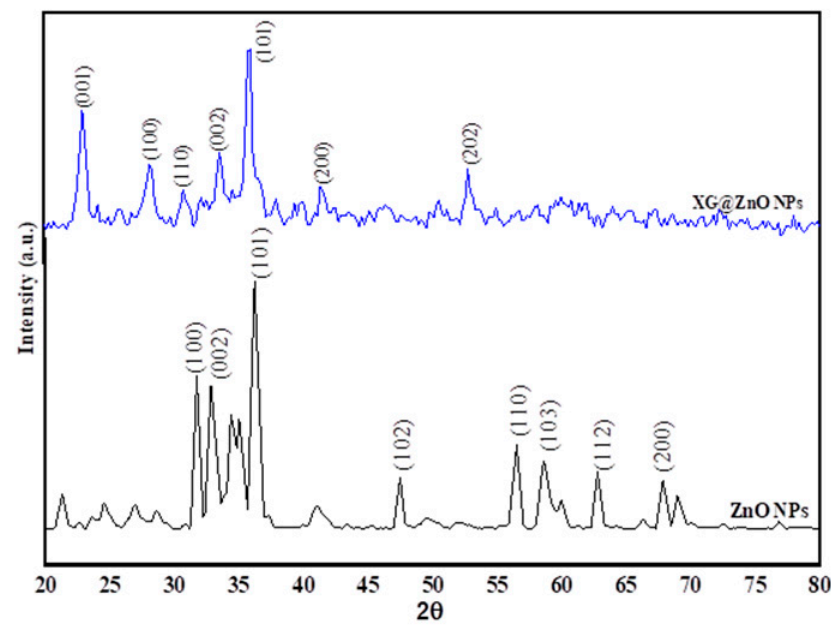

Figure 4. XRD spectra of $\mathrm{ZnO}$ (black line) and ZnO@XG (blue line).

Further information about the lattice structure, deformations on fusion and crystallite size can be obtained using Scherer's formula from Equations (1)-(4) (Scherrer, 1918, [44])

$$
\begin{gathered}
D=\frac{0.9 \lambda}{\beta \cos \theta} \\
\text { DislocationDensity }(\delta)=\frac{1}{D^{2}} \\
\text { InterlayerSpacing }\left(d_{200}\right)=\frac{n \lambda}{2 \operatorname{Sin} \theta} \\
\% \text { Crystallinity }=\frac{\text { AreaUndertheCrystallinePeaks }}{\text { TotalArea }} \times 100
\end{gathered}
$$

where $D$ is the crystal's size, $\lambda$ is the wavelength used (i.e., $1.54 \AA$ ), $\beta$ is the half-width of the most intense peak, and $\theta$ is the angle of diffraction. Using Equations (1)-(4), the average particle size of $\mathrm{ZnO}$ and $\mathrm{ZnO} @ X G$ NPs was found to be $21.5 \pm 1.5$ and $14.7 \pm 1.2 \mathrm{~nm}$. The particle size of $\mathrm{ZnO} @ X \mathrm{XG}$ NPs is also found to be in close agreement with the particle size $(15.73 \mathrm{~nm})$ obtained by TEM analysis. Hence, a decrease in particle size of ZnO NPs from $21.5 \pm 1.5$ to $14.7 \pm 1.2 \mathrm{~nm}$ suggested the successful functionalization and reduction of $\mathrm{Zn}^{2+}$ ions to $\mathrm{ZnO@XG} \mathrm{NPs.} \mathrm{The} \mathrm{formation} \mathrm{of} \mathrm{the} \mathrm{nanoparticles} \mathrm{is}$ also supported by the interlayer spacing value, which decreases from $0.24 \AA$ in bare ZnO NPs to $0.18 \AA$ in ZnO@XG NPs given in Table 1. These interactions of ZnO NPs and XG biopolymer chains resulted in a decreased value of dislocation density from $3.75 \times 10^{15}$ to $2.95 \times 10^{15} \mathrm{~m}^{-2}$ owing to contraction in size and change in crystallinity from $73 \%$ to $46 \%$ due to attachment of amorphous biopolymer chain. The XRD data analysis clearly suggested that there is a successful formation of ZnO NPs followed by surface functionalization by xanthan gum biopolymer chains. 
Table 1. XRD parameters $\mathrm{ZnO}$ and $\mathrm{ZnO@XG} \mathrm{nanocomposite.}$

\begin{tabular}{ccccccc}
\hline Component & $\mathbf{2 \theta}$ & $\begin{array}{c}\text { FWHM } \\
\left(\boldsymbol{\beta}_{\text {hkl }}\right)\end{array}$ & $\begin{array}{c}\text { Interlayer } \\
\text { Spacing }\left(\mathbf{A}^{\circ}\right) \\
\text { at } \mathbf{2 \theta}\end{array}$ & $\begin{array}{c}\text { Crystallite } \\
\text { Size }(\mathbf{n m}) \\
\text { at } \mathbf{2 \theta}\end{array}$ & $\begin{array}{c}\text { Dislocation } \\
\text { Density }(\boldsymbol{\delta}) \times \mathbf{1 0}^{\mathbf{1 5}} \\
\text { Lines }\left(\mathbf{m}^{-\mathbf{2}}\right)\end{array}$ & $\begin{array}{c}\% \\
\text { Crystallinity } \\
(\mathbf{\%})\end{array}$ \\
\hline ZnO NPs & 36.16 & 0.51 & 0.24 & 16.31 & 3.75 & 73 \\
ZnO@XG & 35.89 & 0.45 & 0.18 & 14.89 & 3.12 & 46 \\
\hline
\end{tabular}

\subsection{Morphological Analysis: SEM and TEM}

Scanning electron microscopy (SEM) was employed to observe the surface morphological changes in the material during the solid-state reactions/interactions. Figure $5 \mathrm{a}, \mathrm{b}$ represents the SEM image of ZnO@XG NPs at 7000×, $2 \mu \mathrm{m}$ magnification ranges with EDX spectra within $1-20 \mathrm{KeV}$ energy ranges. Figure 5a exhibits a highly porous surface morphology with a loosely agglomerated distribution of tiny nanowires of ZnO NPs on the surface (white dots) and black dots, represents the XG biopolymer matrix. Further, the atomic percentage of individual constituents used for the formation of ZnO@XG NPs was observed by the energy-dispersive X-rays (EDX) given in Figure 5b. The total output and conclusion received by EDX analysis express the composition of ZnO@XG NPs as C $(72.16 \% \pm 0.42 \%)$, $\mathrm{O}(26.42 \% \pm 1.87 \%)$ and $\mathrm{Zn}(1.42 \% \pm 0.48 \%)$. The transmission electron microscopy (TEM) was used for the elucidation of the optimized diameter and their variation in the XG biopolymer matrix. Figure $5 \mathrm{c}$ represents the TEM image of ZnO@XG NPs at $50 \mathrm{~nm}$ magnification range, which represents the loose agglomeration of tiny circular particles completely distributed along the XG matrix. The average size of nanorods was found to be $16.05 \mathrm{~nm}$, which is in close concurrence with XRD and statistical Gaussian distribution analysis. Figure 5d was utilized to obtain the average particle size of ZnO NPs functionalized with XG biopolymer matrix using statistical domain tools like gaussian distribution. With a frequency of $16 \%$, the average particle size was estimated as $15.73 \mathrm{~nm}$, which is in close concurrence with XRD $(14.7 \mathrm{~nm})$ and TEM results $(16.05 \mathrm{~nm})$.

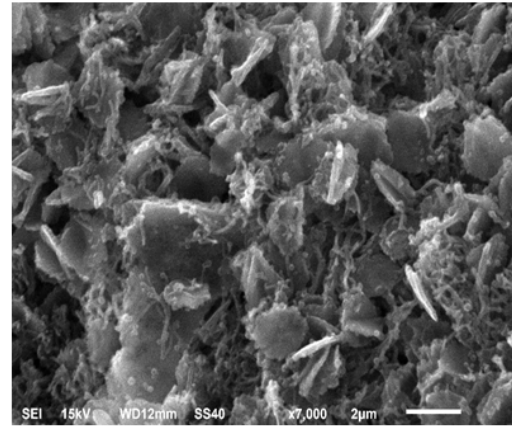

(a)

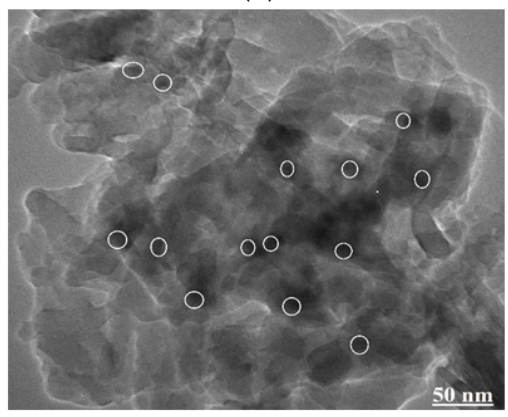

(c)

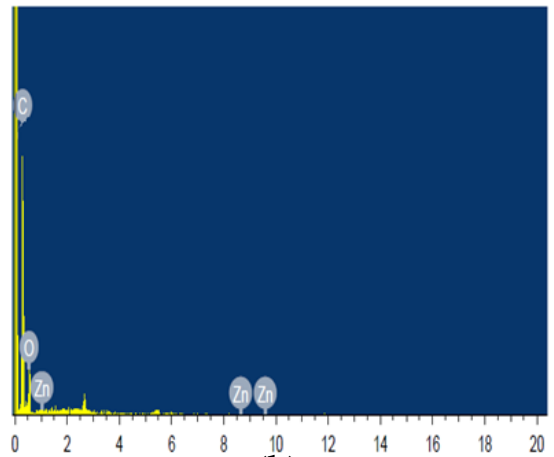

(b)

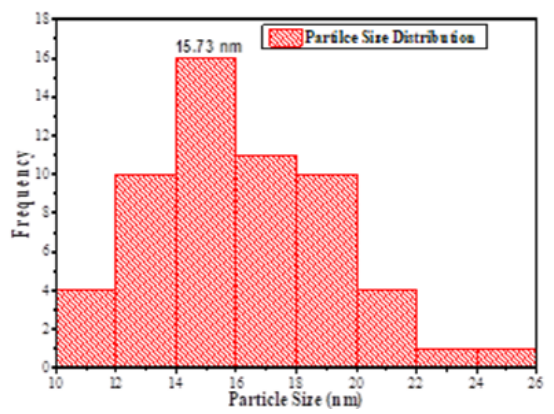

(d)

Figure 5. (a) SEM image of ZnO@XG nanocomposite (b) EDX spectra showing individual constituent elements comprising the material (c) TEM image of ZnO@XG nanocomposite showing the distribution of MSNs in the polymer matrix at $50 \mathrm{~nm}$ magnification range (d) Gaussian distribution of particle size for assessing the average particle size of nanomaterial. 


\subsection{BET}

The Brunauer-Emmett-Teller (BET) isotherm for ZnO@XG NPs was acquired by nitrogen adsorption-desorption method. The BET plot for ZnO@XG NPs given in Figure 6 shows a type IV pattern, which suggested that the synthesized BNC has a nearly mesoporous structure [45]. The value of BET specific surface area for ZnO@XG NPs was found to be $9.24 \mathrm{~m}^{2} \cdot \mathrm{g}^{-1}$ with a total pore volume of $0.045 \mathrm{~cm}^{3} \cdot \mathrm{g}^{-1}$ and pore diameter of $12.87 \mathrm{~nm}$. The reported values of BET specific surface area of bulk $\mathrm{ZnO}$ NPs synthesized by different routes are given as $15.45,34.5,12.998$ and $7.5 \mathrm{~m}^{-2} \cdot \mathrm{g}^{-1}$ [42,46-48]. Hence, the reduction in specific surface area for the current BNC material suggests the incorporation of organic moieties of XG, which leads to blocking some pores due to surface functionalization.

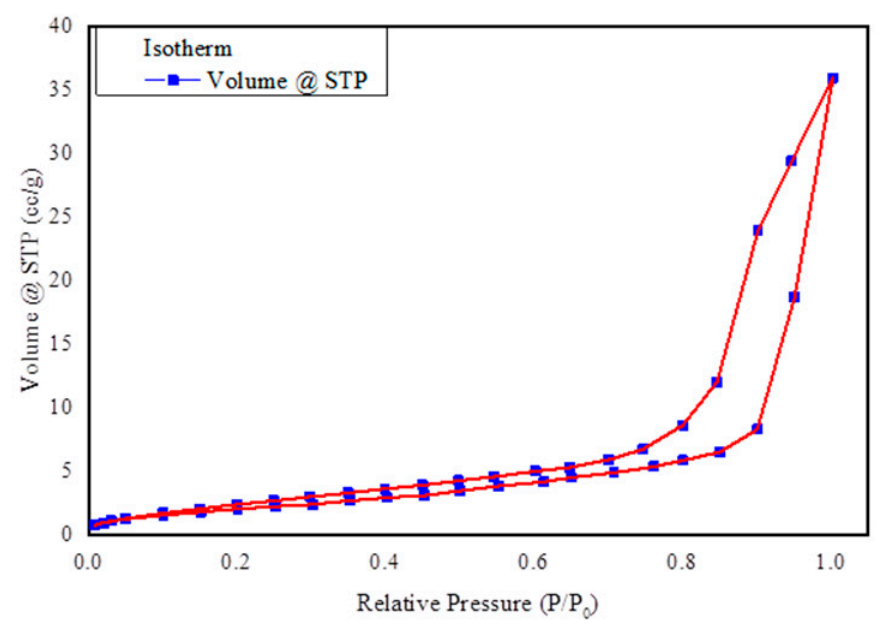

Figure 6. Low-temperature $\mathrm{N}_{2}$ adsorption-desorption plot for $\mathrm{ZnO@XG} \mathrm{nanocomposite.}$

\subsection{MIC}

MIC of the synthesized ZnO@XG was determined against test pathogens C. violaceum and S. marcescens. MIC of ZnO@XG was recorded to be $256 \mu \mathrm{g} / \mathrm{mL}$ against both test pathogens. Since the current investigation was aimed to assess the quorum sensing and biofilm inhibitory of ZnO@XG, subinhibitory concentrations $(0.0625-0.5 x \mathrm{MICs})$ were selected for further microbiological assays.

\subsection{QS Interference in C. violaceum}

Sub-inhibitory concentrations (sub-MICs) of synthesized ZnO@Xanthan gum (ZnO@XG) nanocomposite were assessed for its quorum sensing (QS) inhibitory potential employing biosensor strain C. violaceum ATCC 12472 (CV12472). Production of violacein in C. violacein is regulated by the CviR-dependent quorum sensing system [49]. Impaired violacein production in CV12472 in a concentration-dependent manner is depicted in Figure 7B. Statistically significant $(p \leq 0.05)$ reduction of $15 \%, 33 \%, 47 \%$ and $61 \%$ was over untreated control was recorded at $16,32,64,128 \mu \mathrm{g} / \mathrm{mL}$ concentration of ZnO@XG nanocomposite, respectively. Tested sub-MICs $(16-128 \mu \mathrm{g} / \mathrm{mL})$ did not have any significant effect on the growth of the bacteria (Figure 7A), and thus, it is envisaged that the observed violacein reduction by nanocomposite is due to the quorum sensing interference rather than growth inhibition. Zinc oxide nanoparticles synthesized from plant extracts of Nigella sativa and Ochradenus baccatus have been reported with similar significant violacein inhibition activity (Al-Shabib et al., 2016, 2018, [50]). Chitinase production in C. violaceum is also QS regulated [29]. Chitinolytic activity in C. violaceum treated with sub-MICs of ZnO@XG was quantified using dye-release enzyme assay. The chitinolytic activity was reduced considerably with increasing concentration as compared to the control (Figure 7C). At 16, 32, 64, $128 \mu \mathrm{g} / \mathrm{mL} \mathrm{ZnO} @ X \mathrm{XG}$ treatment, 19\%, 28, 54\%, 70\% reduced chitinolytic activity was observed, respectively. This is probably the first report demonstrating quorum sensing inhibition in C. violaceum by polysaccharide-based zinc oxide nanocomposite. 

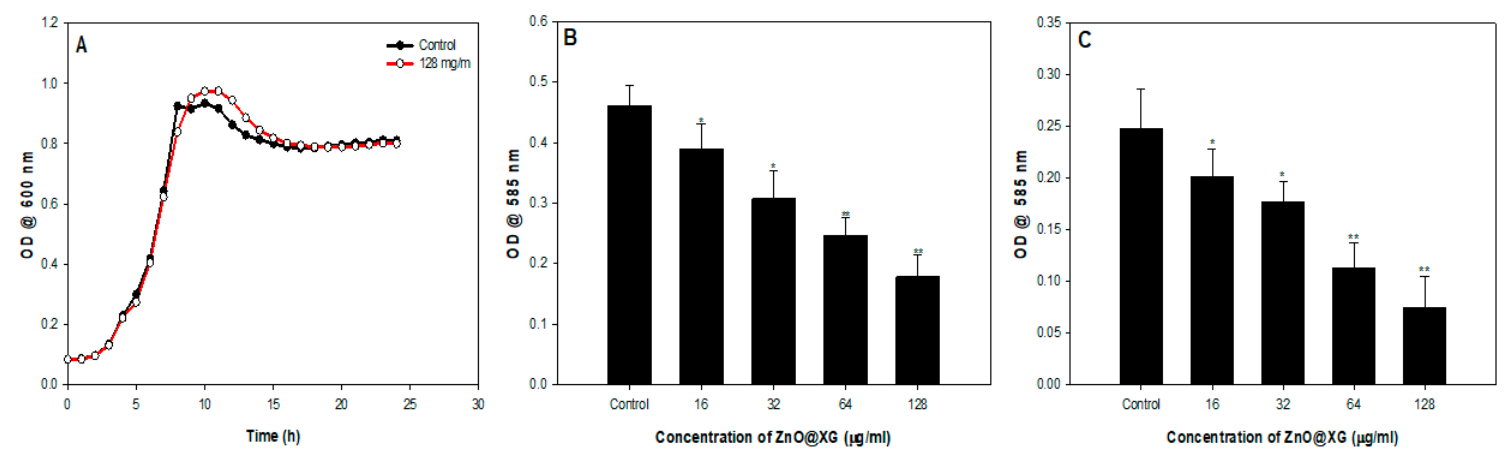

Figure 7. Effect of sub-MICs of ZnO@XG on (A) growth (B) violacein production and (C) chitinase production in C. violaceum ATCC 12,472. * denotes significance at $p \leq 0.05$, and ${ }^{* *}$ denotes significance at $p \leq 0.005$.

\subsection{QS Interference in S. marcescens}

ZnO@XG was assessed for its QS inhibitory activity against virulence factors (prodigiosin and protease) produced by $S$. marcescens. Prodigiosin is a red pigment produced under the control of QS by S. marcescens. It is a vital virulence factor, playing a crucial role in the invasion, survival and pathogenicity of $S$. marcescens [51]. Figure $8 \mathrm{~B}$ shows a concentration-dependent decrease in prodigiosin upon treatment with sub-MICs (16-128 $\mu \mathrm{g} / \mathrm{mL})$ of ZnO@XG. At $128 \mu \mathrm{g} / \mathrm{mL}$ concentration of ZnO@XG, prodigiosin declined by $71 \%$, while at the lowest tested concentration $(16 \mu \mathrm{g} / \mathrm{mL}) 25 \%$ decrease was recorded. Synthesized bio-nanocomposite did not affect the growth of the bacteria significantly at $128 \mu \mathrm{g} / \mathrm{mL}$ (Figure 8A). Our findings are in accordance with the results published on AgNPs synthesized from the extract of Carum copticum. At the highest tested concentration, AgNPs induced a $75 \%$ reduction in prodigiosin as compared to the untreated control [37].
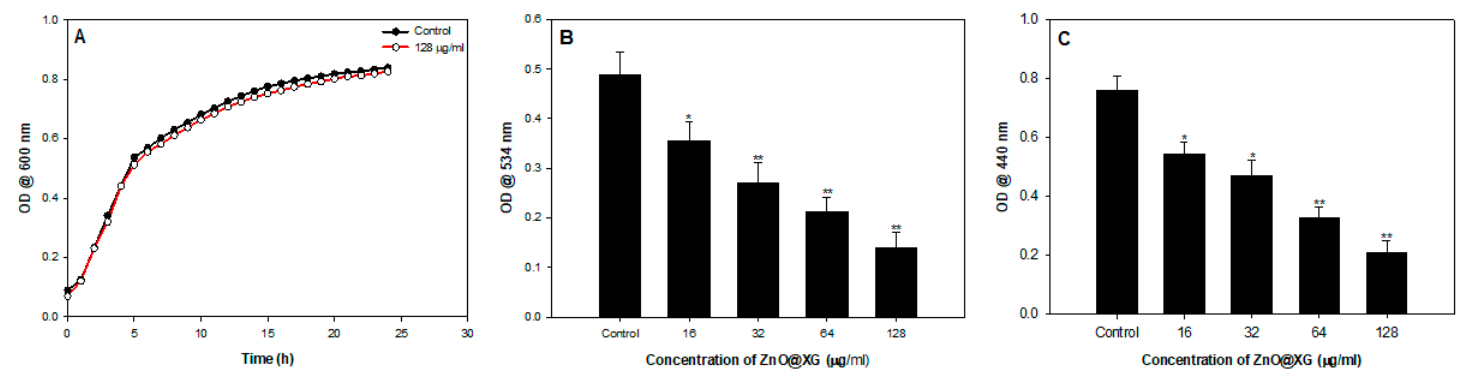

Figure 8. Effect of sub-MICs of ZnO@XG on (A) growth (B) prodigiosin production and (C) protease production in $S$. marcescens ATCC 13880. ${ }^{*}$ denotes significance at $p \leq 0.05$, and ${ }^{* *}$ denotes significance at $p \leq 0.005$.

Protease is another important QS regulated virulence factor produced by S. marcescens. Agents that can suppress the production of protease can be useful in potentiating the innate immune response of the host [52]. Therefore, we evaluated the effect of subinhibitory concentrations of ZnO@XG on protease production. The obtained results demonstrated that the production of protease decreased significantly $(p \leq 0.05)$ at all tested concentrations (Figure $8 \mathrm{C}$ ). Exposure to $128 \mu \mathrm{g} / \mathrm{mL}$ of $\mathrm{ZnO} @ X \mathrm{XG}$ resulted in $72 \%$ less protease production as compared to the untreated control.

\subsection{Effect on Biofilm and Biofilm-Related Virulence Functions}

Considering the results of the virulence assays, we selected $64(0.25 x \mathrm{MIC})$ and $128 \mu \mathrm{g} / \mathrm{mL}(0.5 \mathrm{xMIC})$ for further biofilm-related assays in C. violaceum and S. marcescens. 


\subsubsection{Inhibition of Biofilm Formation}

The potential of the bacteria to cause infections and survive under stressed environments is often related to its capability to form biofilms. Biofilms are complex but organized structures of adherent bacteria forming microcolonies that are enveloped in a self-secreted matrix of EPS [53]. The role of QS in the regulation of various stages of biofilm formation like attachment and maturation is very well documented [54]. Biofilm inhibitory potential of ZnO@XG against both pathogens was evaluated using micro-titer plate (MTP) assay. ZnO@XG exposure caused a significant reduction in the biofilm-forming ability of both pathogens, viz. C. violaceum and S. marcescens (Figure 9A). At $64 \mu \mathrm{g} / \mathrm{mL}$ concentration, biofilm formation in C. violaceum and S. marcescens was inhibited by $49 \%$ and $53 \%$, respectively, while at $128 \mu \mathrm{g} / \mathrm{mL}$, it was further reduced by $67 \%$ (C. violaceum) and $77 \%$ (S. marcescens). Visual confirmation of the quantitative MTP biofilm inhibition assay was obtained using confocal laser scanning microscopic (CLSM) analysis (Figure 9B). CLSM image of the untreated control showed a closely-knit structure having dense aggregation of cells. ZnO@XG treatment resulted in considerably reduced biofilm formation marked by decreased surface coverage, scattered appearance of cells and disturbed integrity of biofilm (Figure 9B). Consistent with this report, Ravindran et al. (2018) reported significantly reduced biofilm formation in S. marcescens treated with AgNPs synthesized from the root extract of Vetiveria zizanioides.
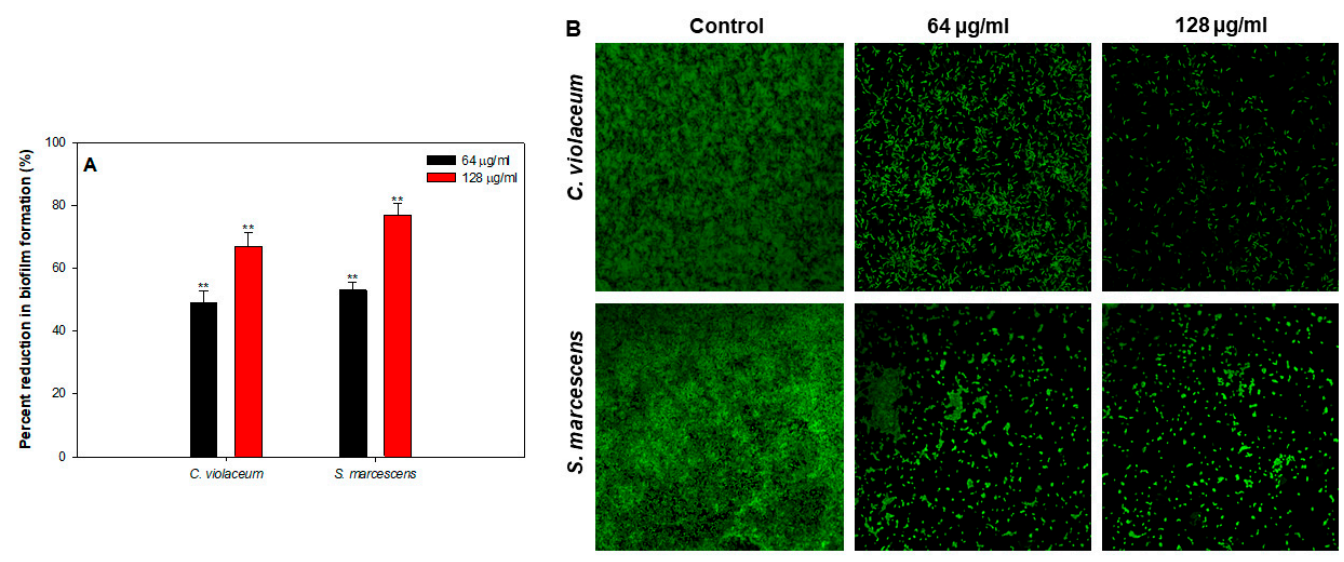

Figure 9. (A) Effect of sub-MICs of ZnO@XG on the biofilm formation of C. violaceum 12472, and S. marcescens ATCC 13880. Data are represented as mean values of triplicate readings, and the bar is the standard deviation. ${ }^{* *}$ denotes significance at $p \leq 0.005$. (B) confocal laser scanning microscopic images of C. violaceum 12472 and S. marcescens ATCC 13880 biofilm in the absence and presence of sub-MIC ZnO@XG.

\subsubsection{EPS Production}

EPS is one of the most vital components of biofilm and plays a critical role in the attachment of cells to the substratum, maintenance of biofilm architecture, obtaining nutrients for cells, and protection of cells from the entry of antimicrobials [55]. EPS extracted from ZnO@XG treated and untreated cultures of C. violaceum, and S. marcescens was quantified, and the concentration-dependent decrease was recorded in both pathogens (Figure 10A). ZnO@XG at $128 \mu \mathrm{g} / \mathrm{mL}$ impaired the EPS production by $66 \%$ and $78 \%$ in C. violaceum and S. marcescens, respectively. Since ZnO@XG effectively reduces EPS production, it could possibly render the biofilm cells susceptible to the action of antibiotics. The observed results are in agreement with the findings of Hasan et al. (2019), [56], wherein dextrin-based poly(methyl methacrylate) grafted silver nanocomposites reduced EPS production significantly in drug-resistant bacteria and Candida albicans. 


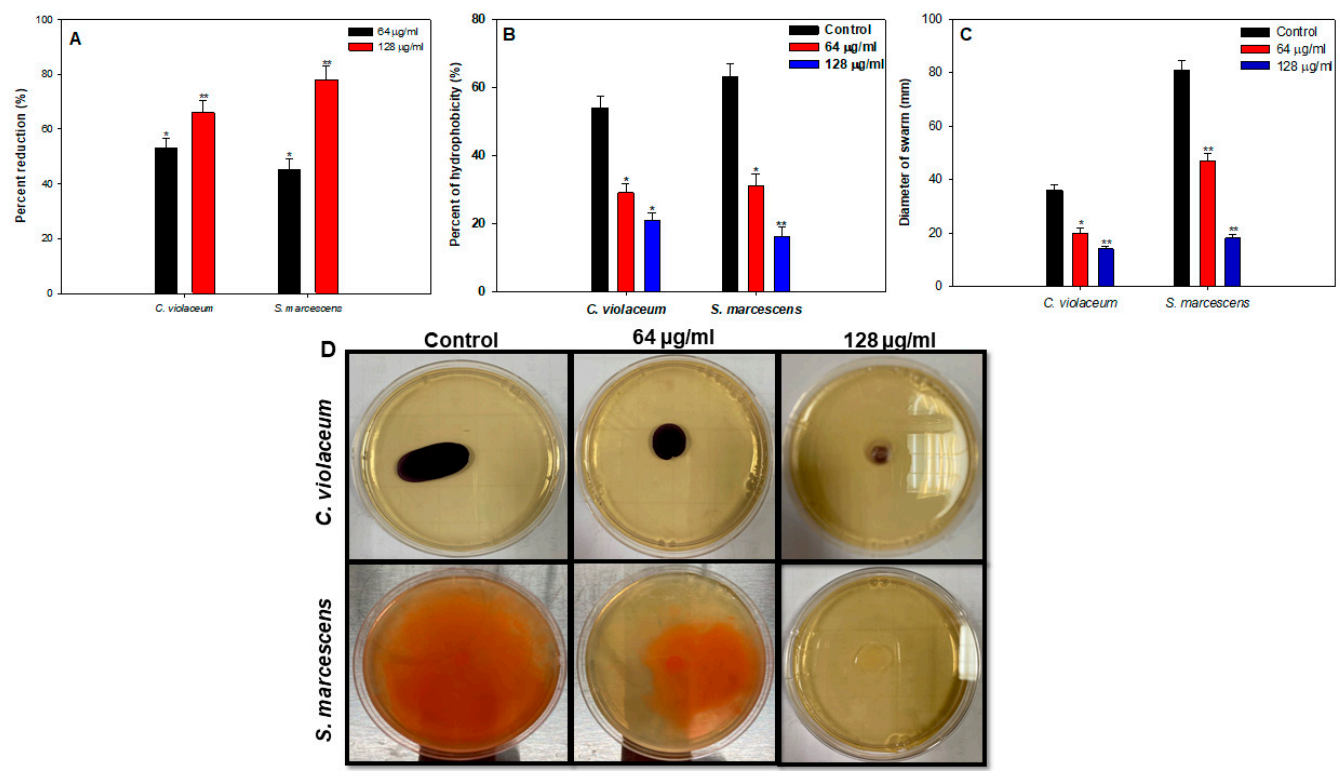

Figure 10. Effect of sub-MICs of ZnO@XG on (A) EPS production (B) cell surface hydrophobicity (C) swarming motility in C. violaceum 12472 and S. marcescens ATCC 13880. Data are represented as mean values of triplicate readings, and the bar is the standard deviation. * denotes significance at $p \leq 0.05$, and ${ }^{* *}$ denotes significance at $p \leq 0.005$. (D) plates demonstrating swarming behavior of C. violaceum 12472 and S. marcescens ATCC 13880 in the absence and presence of sub-MIC ZnO@XG.

\subsubsection{Cell-Surface Hydrophobicity (CSH)}

Cell surface hydrophobicity is another important factor that contributes positively to the adhesion of microbial cells to the substratum. CSH facilitates adhesion by enhancing the hydrophobic interactions between the bacteria and biotic or abiotic surfaces [32]. MATH assay was employed to assess the effect of 64 and $128 \mu \mathrm{g} / \mathrm{mL}$ of $\mathrm{ZnO} @ X \mathrm{XG}$ on CSH of the test pathogens. CSH of untreated controls of C. violaceum and S. marcescens was observed to be $54 \%$ and $63 \%$, respectively (Figure 10B). CSH declined significantly with increasing concentration of $\mathrm{ZnO} @ X \mathrm{XG}$ in both pathogens, and at $128 \mu \mathrm{g} / \mathrm{mL}, 21 \%$ and $16 \%$ CSH was demonstrated by C. violaceum and S. marcescens (Figure 10B). This drop in CSH upon treatment with sub-MICs of ZnO@XG could be responsible for the reduced biofilm formation by the test pathogens. In a study conducted on P. aeruginosa biofilm, it was envisaged that inhibition of $\mathrm{CSH}$ by copper nanoparticles was responsible for its biofilm inhibitory potential (LewisOscar et al., 2015, [57]).

\subsubsection{Swarming Motility}

Swarming motility is flagella-driven distinctive migration behavior in bacteria that plays a vital role in the inception of nosocomial infections. Furthermore, swarming motility is accountable for the enhanced biofilm formation of the pathogenic bacteria by facilitating the attachment of cells to the substratum [58]. Therefore, any interference in swarming behavior could lead to diminished biofilm formation. The diameter of the swarm of C. violaceum and S. marcescens was measured on $0.5 \% \mathrm{LB}$ agar plates with or without sub-MICs of ZnO@XG. In C. violaceum, motility was reduced by $44 \%$ and $61 \%$ at 64 and $128 \mu \mathrm{g} / \mathrm{mL}$ concentrations, respectively (Figure 10C,D). Similarly, swarming was impaired by $42 \%$ and $77 \%$ in S. marcescens at 64 and $128 \mu \mathrm{g} / \mathrm{mL}$ concentrations, respectively (Figure 10C,D). Our findings corroborate well with a previous report demonstrating impaired swarming behavior in P. aeruginosa, C. violaceum, S. marcescens and L. monocytogenes upon treatment with $0.5 x M I C s$ of biologically synthesized tin oxide nanoflowers (Al-Shabib et al., 2018). 


\subsection{Disruption of Preformed Biofilm}

Bacteria residing in the biofilm mode are many-fold more resistant to antibiotics, disinfectants and other bactericidal agents than their planktonic forms [59]. Therefore, disruption of preformed biofilms is rather difficult, and an effective biofilm inhibitory agent must be able to eradicate preformed mature biofilms. ZnO@XG was assessed for its ability to disrupt preformed mature biofilms at sub-MICs (0.25-0.5xMIC). Preformed biofilms were inhibited significantly at the tested concentrations in both pathogens (Figure 11). Observed results demonstrated that at $0.5 \times \mathrm{MIC}(128 \mu \mathrm{g} / \mathrm{mL})$ of $\mathrm{ZnO} @ X \mathrm{XG}$, preformed biofilms were eradicated by $54 \%$ in both $C$. violaceum and $S$. marcescens. EPS matrix envelopes the biofilm cells making them resistant to all kinds of bactericidal and bacteriostatic agents by blocking their entry. The obtained results demonstrate significant disruption of preformed biofilms

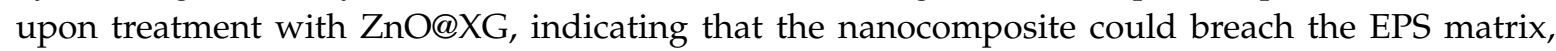
disturb biofilm architecture and expose the bacterial cells rendering them susceptible to antimicrobials. This is probably the first report demonstrating inhibition of preformed biofilm of C. violaceum and S. marcescens by ZnO-biopolymer nanocomposite.

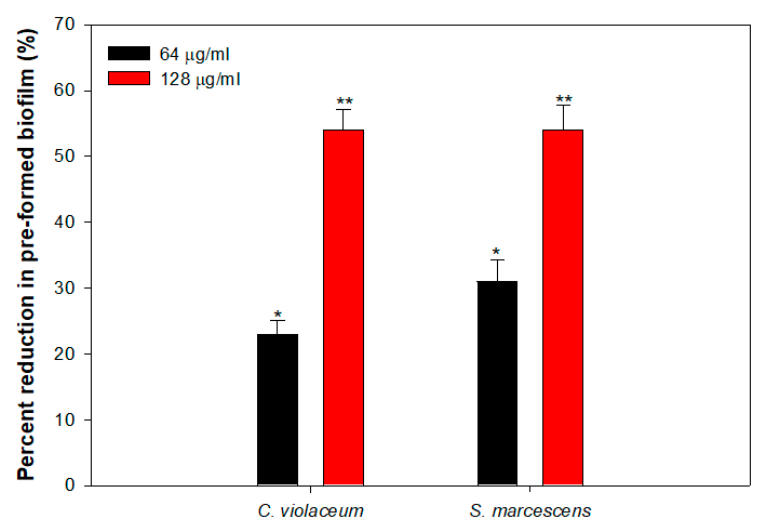

Figure 11. Effect of sub-MICs of ZnO@XG on preformed biofilm of C. violaceum 12472 and S. marcescens ATCC 13880. Data are represented as mean values of triplicate readings, and the bar is the standard deviation. ${ }^{*}$ denotes significance at $p \leq 0.05$, and ${ }^{* *}$ denotes significance at $p \leq 0.005$.

\section{Conclusions}

In conclusion, the study reports the successful formation of ZnO NPs followed by surface functionalization by xanthan gum biopolymer chains. Synthesized ZnO@XG were structurally and morphologically characterized using FTIR, XRD, BET, SEM and TEM. Subinhibitory concentrations of the biopolymer-based $\mathrm{ZnO}$ nanocomposite mitigated QS controlled virulence functions such as violacein, chitinase, prodigiosin, protease, EPS, swarming motility and CSH in pathogens, C. violaceum and S. marcescens. Further, ZnO@XG impaired biofilm formation and eradicated preformed biofilms, eventually leading to reduced pathogenicity of the test pathogens. Thus, it is envisaged that by targeting QS-regulated virulence, the likelihood of development of resistance is less, as no pressure is exerted on the growth of these pathogenic bacteria. Inhibition of virulence functions by ZnO@XG will disarm the bacteria so that they can be more easily eliminated by the host immune response. Thus, the synthesized ZnO@XG nanocomposites could be exploited to combat the threat of persistent bacterial infections and may also prevent the development of drug-resistance. Furthermore, the nanocomposite can be utilized in the food industry to prevent biofilm-based food contamination.

Author Contributions: Conceptualization, F.M.H. and I.H.; methodology, F.M.H., I.H., F.A.Q., R.A.K. and P.A.; software, I.H., R.A.K., and P.A.; validation, F.M.H., I.H., and A.A.; formal analysis, F.M.H. and I.H.; investigation, F.M.H., F.A.Q., and I.H.; resources, A.A.; data curation, F.M.H., F.A.Q., P.A., and I.H.; writing-original draft preparation, F.M.H., F.A.Q., and I.H.; writing-review and editing, F.M.H., F.A.Q., P.A., R.A.K., and I.H.; supervision, A.A.; project administration, A.A.; funding acquisition, A.A. All authors have read and agreed to the published version of the manuscript. 
Funding: This research received no external funding.

Acknowledgments: The authors extend their appreciation to the Deputyship for Research and Innovation, "Ministry of Education" in Saudi Arabia, for funding this research work through project no. IFKSURG-1438-006.

Conflicts of Interest: The authors declare no conflict of interest.

\section{References}

1. Alizadeh-Sani, M.; Ehsani, A.; Moghaddas Kia, E.; Khezerlou, A. Microbial gums: Introducing a novel functional component of edible coatings and packaging. Appl. Microbiol. Biotechnol. 2019, 103, 6853-6866. [CrossRef] [PubMed]

2. Xu, W.; Jin, W.; Huang, K.; Huang, L.; Lou, Y.; Li, J.; Liu, X.; Li, B. Interfacial and emulsion stabilized behavior of lysozyme/xanthan gum nanoparticles. Int. J. Biol. Macromol. 2018, 117, 280-286. [CrossRef] [PubMed]

3. Ghorai, S.; Sarkar, A.; Panda, A.B.; Pal, S. Evaluation of the flocculation characteristics of polyacrylamide grafted xanthan gum/silica hybrid nanocomposite. Ind. Eng. Chem. Res. 2013, 52, 9731-9740. [CrossRef]

4. Joshy, K.S.; Jose, J.; Li, T.; Thomas, M.; Shankregowda, A.M.; Sreekumaran, S.; Kalarikkal, N.; Thomas, S. Application of novel zinc oxide reinforced xanthan gum hybrid system for edible coatings. Int. J. Biol. Macromol. 2020, 151, 806-813. [CrossRef]

5. Al-Shabib, N.A.; Husain, F.M.; Hassan, I.; Khan, M.S.; Ahmed, F.; Qais, F.A.; Oves, M.; Rahman, M.; Khan, R.A.; Khan, A.; et al. Biofabrication of zinc oxide nanoparticle from ochradenus baccatus leaves: Broad-spectrum antibiofilm activity, protein binding studies, and in vivo toxicity and Stress studies. J. Nanomater. 2018, 2018. [CrossRef]

6. Sirelkhatim, A.; Mahmud, S.; Seeni, A.; Kaus, N.H.M.; Ann, L.C.; Bakhori, S.K.M.; Hasan, H.; Mohamad, D. Review on zinc oxide nanoparticles: Antibacterial activity and toxicity mechanism. Nano-Micro Lett. 2015, 7, 219-242. [CrossRef]

7. Vikesland, P.; Garner, E.; Gupta, S.; Kang, S.; Maile-Moskowitz, A.; Zhu, N. Differential drivers of antimicrobial resistance across the world. Acc. Chem. Res. 2019, 52, 916-924. [CrossRef]

8. WHO. The Top 10 Causes of Death; WHO: Geneva, Switzerland, 2018.

9. Dadgostar, P. Antimicrobial resistance: Implications and costs. Infect. Drug Resist. 2019, 12, 3903-3910. [CrossRef]

10. WHO. No Time to Wait: Securing the Future from Drug-Resistant Infections; WHO: Geneva, Switzerland, 2019.

11. Shakoor, S.; Platts-Mills, J.A.; Hasan, R. Antibiotic-resistant enteric infections. Infect. Dis. Clin. N. Am. 2019, 33, 1105-1123. [CrossRef]

12. Andleeb, S.; Majid, M.; Sardar, S. Environmental and public health effects of antibiotics and AMR/ARGs. In Antibiotics and Antimicrobial Resistance Genes in the Environment; Elsevier: Amsterdam, The Netherlands, 2020; pp. 269-291.

13. Ahmad, I.; Qais, F.A.; Abulreesh, H.H.; Ahmad, S.; Rumbaugh, K.P. Antibacterial drug discovery: Perspective insights. In Antibacterial Drug Discovery to Combat MDR; Springer: Singapore, 2019; pp. 1-21.

14. Albrich, W.C.; Monnet, D.L.; Harbarth, S. Antibiotic selection pressure and resistance in streptococcus pneumoniae and streptococcus pyogenes. Emerg. Infect. Dis. 2004, 10, 514-517. [CrossRef]

15. Miller, K. Response of Escherichia coli hypermutators to selection pressure with antimicrobial agents from different classes. J. Antimicrob. Chemother. 2002, 49, 925-934. [CrossRef] [PubMed]

16. Rutherford, S.T.; Bassler, B.L. Bacterial quorum sensing: Its role in virulence and possibilities for its control. Cold Spring Harb. Perspect. Med. 2012, 2, a012427. [CrossRef] [PubMed]

17. Qais, F.A.; Khan, M.S.; Ahmad, I. Nanoparticles as quorum sensing inhibitor: Prospects and limitations. In Biotechnological Applications of Quorum Sensing Inhibitors; Kalia, V.C., Ed.; Springer: Singapore, 2018; pp. 227-244.

18. Davies, D.G.; Parsek, M.R.; Pearson, J.P.; Iglewski, B.H.; Costerton, J.W.; Greenberg, E.P. The involvement of cell-to-cell signals in the development of a bacterial biofilm. Science 1998, 280, 295-298. [CrossRef] [PubMed]

19. Percival, S.L.; Hill, K.E.; Williams, D.W.; Hooper, S.J.; Thomas, D.W.; Costerton, J.W. A review of the scientific evidence for biofilms in wounds. Wound Repair Regen. 2012, 20, 647-657. [CrossRef] [PubMed]

20. Martins, N.; Rodrigues, C.F. Biomaterial-related infections. J. Clin. Med. 2020, 9, 722. [CrossRef] [PubMed] 
21. Lasa, I.; del Pozo, J.L.; Penadés, J.R.; Leiva, J. Biofilms bacterianos e infección. An. Sist. Sanit. Navar. 2005, 28, 163-175. [CrossRef]

22. Qais, F.A.; Ahmad, I. Green synthesis of metal nanoparticles: Characterization and their antibacterial efficacy. In Antibacterial Drug Discovery to Combat MDR; Springer: Singapore, 2019; pp. 635-680.

23. Al-Shabib, N.A.; Husain, F.M.; Ahmad, N.; Qais, F.A.; Khan, A.; Khan, A.; Khan, M.S.; Khan, J.M.; Shahzad, S.A.; Ahmad, I. Facile synthesis of tin oxide hollow nanoflowers interfering with quorum sensing-regulated functions and bacterial biofilms. J. Nanomater. 2018, 2018. [CrossRef]

24. Husain, F.M.; Ansari, A.A.; Khan, A.; Ahmad, N.; Albadri, A.; Albalawi, T.H. Mitigation of acyl-homoserine lactone (AHL) based bacterial quorum sensing, virulence functions, and biofilm formation by yttrium oxide core/shell nanospheres: Novel approach to combat drug resistance. Sci. Rep. 2019, 9, 1-10. [CrossRef]

25. Basha, S.K.; Lakshmi, K.V.; Kumari, V.S. Ammonia sensor and antibacterial activities of green zinc oxide nanoparticles. Sens. Bio-Sens. Res. 2016, 10, 34-40. [CrossRef]

26. Andrews, J.M. Determination of minimum inhibitory concentrations. J. Antimicrob. Chemother. 2001, 48, 5-16. [CrossRef]

27. Husain, F.M.; Ahmad, I. Doxycycline interferes with quorum sensing-mediated virulence factors and biofilm formation in Gram-negative bacteria. World J. Microbiol. Biotechnol. 2013, 29. [CrossRef] [PubMed]

28. Matz, C.; Deines, P.; Boenigk, J.; Arndt, H.; Eberl, L.; Kjelleberg, S.; Jurgens, K. Impact of violacein-producing bacteria on survival and feeding of bacterivorous nanoflagellates. Appl. Environ. Microbiol. 2004, 70, 1593-1599. [CrossRef] [PubMed]

29. Chernin, L.S.; Winson, M.K.; Thompson, J.M.; Haran, S.; Bycroft, B.W.; Chet, I.; Williams, P.; Stewart, G.S.A.B. Chitinolytic activity in chromobacterium violaceum: Substrate analysis and regulation by quorum sensing. J. Bacteriol. 1998, 180, 4435-4441. [CrossRef]

30. Champalal, L.; Kumar, U.S.; Krishnan, N.; Vaseeharan, B.; Mariappanadar, V.; Raman, P. Modulation of quorum sensing-controlled virulence factors in chromobacterium violaceum by selective amino acids. FEMS Microbiol. Lett. 2018, 365, 1-8. [CrossRef]

31. Morohoshi, T.; Shiono, T.; Takidouchi, K.; Kato, M.; Kato, N.; Kato, J.; Ikeda, T. Inhibition of quorum sensing in serratia marcescens AS-1 by synthetic analogs of N-acylhomoserine lactone. Appl. Environ. Microbiol. 2007, 73, 6339-6344. [CrossRef] [PubMed]

32. Ravindran, D.; Ramanathan, S.; Arunachalam, K.; Jeyaraj, G.P.; Shunmugiah, K.P.; Arumugam, V.R. Phytosynthesized silver nanoparticles as antiquorum sensing and antibiofilm agent against the nosocomial pathogen Serratia marcescens: An in vitro study. J. Appl. Microbiol. 2018, 124, 1425-1440. [CrossRef]

33. Al-Shabib, N.A.; Husain, F.M.; Nadeem, M.; Khan, M.S.; Al-Qurainy, F.; Alyousef, A.A.; Arshad, M.; Khan, A.; Khan, J.M.; Alam, P.; et al. Bio-inspired facile fabrication of silver nanoparticles from: In vitro grown shoots of Tamarix nilotica: Explication of its potential in impeding growth and biofilms of Listeria monocytogenes and assessment of wound healing ability. RSC Adv. 2020, 10. [CrossRef]

34. Al-Shabib, N.A.; Husain, F.M.; Qais, F.A.; Ahmad, N.; Khan, A.; Alyousef, A.A.; Arshad, M.; Noor, S.; Khan, J.M.; Alam, P.; et al. Phyto-mediated synthesis of porous titanium dioxide nanoparticles from withania somnifera root extract: Broad-spectrum attenuation of biofilm and cytotoxic properties against HepG2 cell lines. Front. Microbiol. 2020, 11, 1680. [CrossRef]

35. Husain, F.M.; Ahmad, I.; Baig, M.H.; Khan, M.S.; Khan, M.S.; Hassan, I.; Al-Shabib, N.A. Broad-spectrum inhibition of AHL-regulated virulence factors and biofilms by sub-inhibitory concentrations of ceftazidime. RSC Adv. 2016, 6. [CrossRef]

36. DuBois, M.; Gilles, K.A.; Hamilton, J.K.; Rebers, P.A.; Smith, F. Colorimetric method for determination of sugars and related substances. Anal. Chem. 1956, 28, 350-356. [CrossRef]

37. Qais, F.A.; Shafiq, A.; Ahmad, I.; Husain, F.M.; Khan, R.A.; Hassan, I. Green synthesis of silver nanoparticles using Carum copticum: Assessment of its quorum sensing and biofilm inhibitory potential against gram negative bacterial pathogens. Microb. Pathog. 2020, 144, 104172. [CrossRef] [PubMed]

38. Rosenberg, M.; Gutnick, D.; Rosenberg, E. Adherence of bacteria to hydrocarbons: A simple method for measuring cell-surface hydrophobicity. FEMS Microbiol. Lett. 1980, 9, 29-33. [CrossRef] 
39. Al-Shabib, N.A.; Husain, F.M.; Rehman, M.T.; Alyousef, A.A.; Arshad, M.; Khan, A.; Masood Khan, J.; Alam, P.; Albalawi, T.A.; Shahzad, S.A.; et al. Food color 'Azorubine' interferes with quorum sensing regulated functions and obliterates biofilm formed by food associated bacteria: An in vitro and in silico approach. Saudi J. Biol. Sci. 2020, 27, 1080-1090. [CrossRef] [PubMed]

40. Mohsin, A.; Zhang, K.; Hu, J.; Tariq, M.; Zaman, W.Q.; Khan, I.M.; Zhuang, Y.; Guo, M. Optimized biosynthesis of xanthan via effective valorization of orange peels using response surface methodology: A kinetic model approach. Carbohydr. Polym. 2018, 181, 793-800. [CrossRef]

41. Chikkanna, M.M.; Neelagund, S.E.; Rajashekarappa, K.K. Green synthesis of Zinc oxide nanoparticles (ZnO NPs) and their biological activity. SN Appl. Sci. 2019, 1, 117. [CrossRef]

42. Thirumavalavan, M.; Huang, K.-L.; Lee, J.-F. Preparation and morphology studies of nano Zinc oxide obtained using native and modified chitosans. Materials 2013, 6, 4198-4212. [CrossRef]

43. Muhammad, W.; Ullah, N.; Haroon, M.; Abbasi, B.H. Optical, morphological and biological analysis of zinc oxide nanoparticles (ZnO NPs) using Papaver somniferum L. RSC Adv. 2019, 9, 29541-29548. [CrossRef]

44. Scherrer, P. Estimation of the size and internal structure of colloidal particles by means of X rays. Nachs. Gissel. Wiss. Gott. 1918, 26, 98-100.

45. Meng, A.; Xing, J.; Li, Z.; Li, Q. Cr-doped ZnO nanoparticles: Synthesis, characterization, adsorption property, and recyclability. ACS Appl. Mater. Interfaces 2015, 7, 27449-27457. [CrossRef]

46. Wang, J.; Xia, Y.; Dong, Y.; Chen, R.; Xiang, L.; Komarneni, S. Defect-rich ZnO nanosheets of high surface area as an efficient visible-light photocatalyst. Appl. Catal. B Environ. 2016, 192, 8-16. [CrossRef]

47. Le, T.K.; Nguyen, T.M.T.; Nguyen, H.T.P.; Nguyen, T.K.L.; Lund, T.; Nguyen, H.K.H.; Huynh, T.K.X. Enhanced photocatalytic activity of $\mathrm{ZnO}$ nanoparticles by surface modification with $\mathrm{KF}$ using thermal shock method. Arab. J. Chem. 2020, 13, 1032-1039. [CrossRef]

48. Nagaraju, P.; Puttaiah, S.H.; Wantala, K.; Shahmoradi, B. Preparation of modified ZnO nanoparticles for photocatalytic degradation of chlorobenzene. Appl. Water Sci. 2020, 10, 137. [CrossRef]

49. McLean, R.J.C.; Pierson, L.S.; Fuqua, C. A simple screening protocol for the identification of quorum signal antagonists. J. Microbiol. Methods 2004, 58, 351-360. [CrossRef] [PubMed]

50. Al-Shabib, N.A.; Husain, F.M.; Ahmed, F.; Khan, R.A.; Ahmad, I.; Alsharaeh, E.; Khan, M.S.; Hussain, A.; Rehman, M.T.; Yusuf, M.; et al. Biogenic synthesis of Zinc oxide nanostructures from Nigella sativa seed: Prospective role as food packaging material inhibiting broad-spectrum quorum sensing and biofilm. Sci. Rep. 2016, 6. [CrossRef]

51. Liu, G.Y.; Nizet, V. Color me bad: Microbial pigments as virulence factors. Trends Microbiol. 2009, 17, 406-413. [CrossRef]

52. Sethupathy, S.; Ananthi, S.; Selvaraj, A.; Shanmuganathan, B.; Vigneshwari, L.; Balamurugan, K.; Mahalingam, S.; Pandian, S.K. Vanillic acid from Actinidia deliciosa impedes virulence in Serratia marcescens by affecting S-layer, flagellin and fatty acid biosynthesis proteins. Sci. Rep. 2017, 7, 1-17. [CrossRef]

53. Hall-Stoodley, L.; Costerton, J.W.; Stoodley, P. Bacterial biofilms: From the natural environment to infectious diseases. Nat. Rev. Microbiol. 2004, 2, 95-108. [CrossRef]

54. Rice, S.A.; Koh, K.S.; Queck, S.Y.; Labbate, M.; Lam, K.W.; Kjelleberg, S. Biofilm formation and sloughing in serratia marcescens are controlled by quorum sensing and nutrient cues. J. Bacteriol. 2005, 187, 3477-3485. [CrossRef]

55. Zhou, J.-W.; Ruan, L.-Y.; Chen, H.-J.; Luo, H.-Z.; Jiang, H.; Wang, J.-S.; Jia, A.-Q. Inhibition of quorum sensing and virulence in serratia marcescens by hordenine. J. Agric. Food Chem. 2019, 67, 784-795. [CrossRef]

56. Hasan, I.; Qais, F.A.; Husain, F.M.; Khan, R.A.; Alsalme, A.; Alenazi, B.; Usman, M.; Jaafar, M.H.; Ahmad, I. Eco-friendly green synthesis of dextrin based poly (methyl methacrylate) grafted silver nanocomposites and their antibacterial and antibiofilm efficacy against multi-drug resistance pathogens. J. Clean. Prod. 2019, 230, 1148-1155. [CrossRef]

57. LewisOscar, F.; MubarakAli, D.; Nithya, C.; Priyanka, R.; Gopinath, V.; Alharbi, N.S.; Thajuddin, N. One pot synthesis and anti-biofilm potential of copper nanoparticles (CuNPs) against clinical strains of Pseudomonas aeruginosa. Biofouling 2015, 31, 379-391. [CrossRef] [PubMed]

58. Van Houdt, R.; Givskov, M.; Michiels, C.W. Quorum sensing in Serratia. FEMS Microbiol. Rev. 2007, 31, 407-424. [CrossRef] [PubMed] 
59. Fux, C.A.; Costerton, J.W.; Stewart, P.S.; Stoodley, P. Survival strategies of infectious biofilms. Trends Microbiol. 2005, 13, 34-40. [CrossRef] [PubMed]

Publisher's Note: MDPI stays neutral with regard to jurisdictional claims in published maps and institutional affiliations.

(C) 2020 by the authors. Licensee MDPI, Basel, Switzerland. This article is an open access article distributed under the terms and conditions of the Creative Commons Attribution (CC BY) license (http://creativecommons.org/licenses/by/4.0/). 